\title{
What this construction needs is generalized
}

\author{
MICHAEL P. KASCHAK \\ Florida State University, Tallahassee, Florida
}

\begin{abstract}
What is the nature of the knowledge that readers acquire as they learn to comprehend a novel construction in their native language? This question was explored in two experiments that examined the extent to which readers who learn a new construction are able to extend it to sentence contexts other than the one in which it initially appeared. Readers were trained on the needs construction ("The meal needs cooked given that dinner is in an hour") and then were presented with examples of the construction in a different sentential context ("John thinks that what the meal needs is cooked given that dinner is in an hour"). The results show that readers have little difficulty comprehending the needs construction in the new context, even when the construction is used with a different verb. These findings are discussed with respect to theories of structural priming and sentence processing.
\end{abstract}

Most of the research conducted on sentence processing over the past several decades has focused on the comprehension of language that is idealized and well formed. This research has led to the development of detailed theories of the processes involved as comprehenders translate linguistic input into meaning (see, e.g., Frazier \& Clifton, 1996; MacDonald, Pearlmutter, \& Seidenberg, 1994). At the same time, the focus on idealized and well-formed sentences brought about a relative neglect of the means through which comprehenders handle linguistic input that is novel, unusual, or otherwise nonoptimal. The nonoptimal input with which comprehenders might be faced includes (among other examples) novel words (e.g., Chaffin, Morris, \& Seely, 2001; Kaschak \& Glenberg, 2000) and a host of phonological, lexical, and syntactic peculiarities that may be encountered when one comes into contact with language from a speaker or dialect that is unfamiliar (e.g., Kaschak \& Glenberg, 2004; Labov, 1994; Nygaard \& Pisoni, 1998). Presently, relatively little is known about how comprehenders adapt when presented with unfamiliar or novel linguistic structures, especially in the case of syntactic constructions.

Kaschak and Glenberg (2004) have reported an initial study of the processing involved as readers are repeatedly exposed to (and learn to comprehend) a novel syntactic construction in their native language: the needs construction (e.g., "The meal needs cooked"). ${ }^{1}$ These experiments were a rough analogue to situations in which comprehenders come into contact with a feature of an unfamiliar dialect of English (in this case, Upper Mid-

Thanks to Renrick Loney, Kristin Borreggine, Martin Pickering, and two anonymous reviewers for their insightful feedback on the manuscript. Thanks also to the students who ran the experiments reported here (Wendell Williams, Denae van Etten, Sarah Anderson, Nancy Morrow, Rick Tuten, Travis Snyder, Emily Fairbanks, and Jennifer Cyriac). Correspondence concerning this article should be sent to M. Kaschak, Department of Psychology, Florida State University, Tallahassee, FL 32310 (e-mail: kaschak@psy.fsu.edu). western adults were exposed to a construction from the Northern Midlands dialect of American English-most famously, around Pittsburgh; Murray, Frazier, \& Simon, 1996). Beyond simply showing that readers can learn to comprehend a novel construction, the results of Kaschak and Glenberg's (2004) experiments suggested that the participants' learning of the needs construction was at least somewhat general. In one experiment, the learners' understanding of the needs construction generalized across modalities (spoken to written language). A subsequent experiment showed that the participants who were trained on the needs construction with sentences such as Sentence 1 had little difficulty comprehending the construction when it was presented with a new verb (as in Sentence 2):

1. The meal needs cooked given that dinner is in an hour.

2. The dog wants walked before we go to the movies.

Thus, the participants generalized the needs construction to at least one other verb, wants.

The experiments reported below were designed to further test learner's ability to generalize the needs construction. The question of interest is whether readers' developing knowledge of the needs construction is tied to the surface form (i.e., the ordering of the words) and sentential context of the construction as it was initially encountered or whether it is abstract and general enough to support the facile comprehension of the construction when it appears with a different surface form and in a different sentential context. Participants were trained on the needs construction with examples such as Sentence 1, and then were presented with examples of the construction such as Sentence 3:

\section{John thinks that what the meal needs is cooked given that dinner is in an hour.}

In Sentence 1, the needs construction is the main clause of a canonical active sentence. In Sentence 3, the needs construction appears with a different surface form (the verb needs and the following participle are now separated from 
each other) and a different syntactic structure (a pseudocleft construction) and is presented within the subordinate clause of a verb-complement construction. The pseudocleft construction was used in these studies because it distorts the surface form of the needs construction and because generalizing the construction to the pseudocleft form is something that speakers of the Northern Midlands dialect of American English are attested to do (Murray \& Simon, 2001).

If participants whose only exposure to the needs construction is through sentences such as Sentence 1 comprehend sentences such as Sentence 3 with little difficulty, it suggests that they have learned something about the construction that is more abstract than simply noting that the copula between needs and the participle can be omitted. Generalization between Sentences 1 and 2 could be accomplished via a heuristic related to the surface ordering of the words (e.g., needs or similar verbs can be followed directly by a participle), but generalization between Sentences 1 and 3 cannot. $^{2}$ Due to the difference in surface form between the canonical active and pseudocleft versions of the construction, learners must have acquired an abstract representation of the needs construction that is subject to the same syntactic principles that other constructions in the readers' grammar are.

The present study also has implications for the role of structural priming in sentence processing. Structural priming refers to the facilitated processing of a syntactic structure on the basis of prior experience with that structure (Bock, 1986). This phenomenon is most well studied in language production, where it has been shown that the likelihood of producing a particular syntactic structure is increased by prior exposure to another example of that same structure. For example, after using a double-object construction to describe a transfer event ("Meghan gave her mom a toy"), one is more likely to produce another double object to describe a subsequent transfer event ("The sailor sent his partner a telegram") than to do so with the prepositional object variant of the construction ("The sailor sent a telegram to his partner"). This finding (involving a number of constructions) is well documented in the literature (e.g., Bock, 1986, 1989; Bock \& Griffin, 2000; Branigan, Pickering, \& Cleland, 2000; Kaschak, Loney, \& Borreggine, 2006; Pickering \& Branigan, 1998). Structural priming has also been reported in language comprehension (e.g., Branigan, Pickering, \& McLean, 2005; Carey, Mehler, \& Bever, 1970), where a particular syntactic structure is processed with more ease, given prior exposure to that construction.

The experiments presented below (and in Kaschak \& Glenberg, 2004) did not have the same structure as a typical structural priming experiment. Nonetheless, structural priming might play a role as readers learn to comprehend the needs construction. Exposure to one example of the needs construction serves as a prime that facilitates processing of the next example of the construction, and so on through the experiment. The claim that structural priming facilitates learning of the needs construction is consistent with reports from child language acquisition. For example, Brooks and Tomasello (1999) have shown that children's learning of the passive construction can be facilitated by structural priming (see Savage, Lieven, Theakston, \& Tomasello, 2003, for further evidence of the role of structural priming in language acquisition).

There are several parallels between participants' learning of the needs construction and the learning shown in the structural priming literature. Kaschak and Glenberg (2004) reported that learning of the needs construction transfers between spoken and written language and transfers to at least one other verb. Similarly, Cleland and Pickering (2006) have reported structural priming across spoken and written modalities, and structural priming across verbs has been reported in many places (e.g., Bock, 1986; Bock \& Griffin, 2000; Pickering \& Branigan, 1998). The participants in Kaschak and Glenberg's (2004) experiments showed more rapid gains in processing the (unfamiliar) needs construction than in processing constructions with which they were already familiar. This is in keeping with recent claims that syntactic priming effects are stronger for less preferred constructions than for more common constructions (Ferreira, 2003). Although the parallels between Kaschak and Glenberg's (2004) results and the data on structural priming rely on comparisons between tasks involving language production and language comprehension, the fact that priming can be observed from comprehension to production (Branigan et al., 2000; Cleland \& Pickering, 2003) suggests that priming in comprehension and production rely on the same (or similar) mechanisms and thus implies that similar effects should be observed in comprehension and production tasks.

For the present purposes, the most relevant demonstration of structural priming comes from Branigan, Pickering, McLean, and Stewart (in press). Branigan et al. (in press) show that structural priming can occur even when the prime structure and the target structure appear in different sentential contexts. A double-object construction presented as the main clause of a sentence (e.g., "The man gave the baby a toy") can prime the use of another double-object construction within a subordinate clause (e.g., "John thinks that the man gave the baby a toy"), and vice versa. If the same mechanisms are responsible for producing structural priming in language comprehension and production, the results of Branigan et al.'s (in press) study provide a precedent for predicting that readers who are trained on the needs construction should generalize the construction to a different sentential context.

\section{EXPERIMENT 1}

Experiment 1 was conducted in two phases. In Phase 1, half of the participants (needs training condition) were introduced to the needs construction through sentences such as Sentence 1, repeated below:

\section{The meal needs cooked given that dinner is in an hour.}

The other half of the participants (control training condition) read the same training sentences, but in the form standardly used in their dialect of English (as in Sentence 4): 


\section{The meal needs to be cooked given that dinner is in an} hour.

The participants encountered these sentences in a wordby-word reading task. It was expected that the participants in the needs training condition would initially experience difficulty comprehending the sentence, particularly at the word given. The processing difficulty is localized to this region of the sentence because of an ambiguity between the needs construction and what Kaschak and Glenberg (2004) called the modifier construction, in which the participle (cooked) is used as a modifier for a subsequent noun (e.g., The meal needs cooked vegetables to keep the guests happy). Readers who are unfamiliar with the needs construction interpret the words, "The meal needs cooked ..." as the beginning of the modifier construction, only to garden path on the word given when it turns out that this interpretation is incorrect. As readers become familiar with the needs construction, they are less likely to make this initial misinterpretation, attenuating the processing difficulty in this region of the sentence.

Phase 2 of the experiment followed directly from Phase 1. The participants in both training conditions were presented with the needs construction in a pseudocleft form within a verb-complement construction, as in Sentence 3, repeated below:

\section{John thinks that what the meal needs is cooked given that dinner is in an hour.}

If the readers' knowledge of the needs construction is limited to the surface form and syntactic context of the canonical active needs sentences encountered in Phase 1, they should experience some degree of processing difficulty (relative to their processing of the needs construction at the end of the training phase) in reading sentences such as Sentence 3. However, if the participants' learning of the needs construction involves the development of abstract knowledge about the structure of the construction, they should have little difficulty with the sentences presented in Phase 2 of the experiment.

\section{Method}

Participants. The participants were 48 introductory psychology students from Florida State University ( 24 in each training condition). They received course credit in exchange for their participation. All the participants were native speakers of English, and all were residents of Florida. It was assumed that the residents of Florida would be unfamiliar with the needs construction. This assumption was based on maps showing attestations of the needs construction presented by Murray et al. (1996) and by surveying the linguistic intuitions of native Floridians who had never been to the Northern Midlands dialect region of the United States.

Materials. Fifty sentences were generated for this experiment. Ten sentences were generated for the Phase 1 training on the needs construction (e.g., "The meal needs cooked given that dinner is in an hour"). The control training condition used the same 10 sentences, except that the control sentences had to be inserted after needs. Ten transfer sentences were generated for Phase 2 (e.g., "John thinks that what the meal needs is cooked given that dinner is in an hour"). The remaining 30 sentences were fillers of various sorts (e.g., "The sheep walked across the yard to exit through the gate"). The fillers did not use the verb needs (or wants in the case of Experiment 2). In addition, a comprehension question was written for each sentence (e.g., "The meal needs cooked given that dinner is in an hour" was followed by "Is dinner in an hour?"). All the critical sentences are presented in the Appendix.

Procedure. The participants were told that they were going to read a series of sentences word by word. They were told to read the sentences as quickly and carefully as possible. A trial began with a prompt to get ready for the sentence. The participant pressed the space bar of the computer keyboard to see the first word of the sentence. They were told to press the space bar to move to each subsequent word in the sentence. The display of words in the sentence was noncumulative. At the end of the sentence, the words, "*** GOT IT?***" appeared on the screen. The participants were told to press the space bar again when they were sure that they understood the sentence. Once they pressed the space bar, the comprehension question appeared on the screen. The participants responded by pressing keys labeled "Y" or "N" on the keyboard.

The order of presentation of the sentences was randomized individually for each participant, with the constraint that the needs training sentences were presented only in the first 25 trials of the experiment (10 needs sentences and 15 fillers) and the pseudocleft needs sentences were presented only in the last 25 trials of the experiment (10 transfer sentences and 15 fillers). Presentation of the items was randomized in blocks of 5 trials. Within each block, the participants read 2 critical sentences and 3 fillers.

The variables of interest in this experiment were the reading times for the five words in the region of interest of the critical sentences (“... needs cooked given that dinner..."). These positions will be referred to by name (needs, cooked, etc.) in the analyses, tables, and figures that summarize the data. To compare the reading times for the needs sentences in Phase 1 with those in Phase 2, the region of interest in the transfer sentences from Phase 2 was aligned with the region of interest from the training sentences. The region of interest for the transfer sentences spanned the words "... needs is cooked given that dinner...," where needs is in the initial position of the region, $i s$ is skipped in the analysis, cooked is in the second position of the region, and so on.

Design and Analysis. To control for length effects, a variant of the procedure used by Garnsey, Pearlmutter, Myers, and Lotocky (1997) was employed. The reading times for all the words for which reading times were recorded (for critical sentences and fillers) were entered into a regression analysis in which word length (in characters) and sentence position were used to predict reading times. Whereas Garnsey et al. performed a separate regression analysis for each participant, the reading times for all the participants in the experiment were entered into a single regression analysis (see Kaschak \& Glenberg, 2004, for a discussion of the rationale behind this analysis). The residuals from this regression analysis were entered into the analyses reported below.

Three primary analyses were conducted. The first focused exclusively on Phase 1. A 2 (training: needs or control) $\times 3$ (time period: Critical Trials $1-3,4-7$, or 8-10) mixed factor ANOVA was conducted on each region of the sentence, with training as a between-participants variable. For the analysis by items, both training and time were within-items factors. In comparing the reading of the needs and the control sentences, the words to be were excluded from the data for the control sentences, so that both sentence types were analyzed on the words needs, cooked, given, that, and dinner. This analysis was aimed at observing the learning effect on the needs construction. The second analyses involved the data from the end of Phase 1 (Critical Trials 8-10) and the first half of Phase 2 (Critical Trials 1-5 from Phase 2). These analyses were intended to test for differential effects in moving from the training sentences (needs or control) to the transfer sentences. A 2 (training: needs or control) $\times 2$ (time: end of Phase 1 or beginning of Phase 2) mixed factor ANOVA was conducted on each region of the sentence, with training as a between-participants variable. For the analysis by items, training was within items, but time was between items. The third analyses 
involved the data from Phase 2. A 2 (training: needs or control) $\times 2$ (time period: Critical Trials 1-5 or Critical Trials 6-10) mixed factor ANOVA was conducted on each region of the sentence, with training as a between-participants variable (both factors are within items). The purpose of this analysis was to determine how processing of the pseudocleft needs sentences changed across time.

Follow-up comparisons between individual cells of the design were conducted as simple main effects, calculated as per Keppel (1991). Simple main effects computed across within-participants factors were analyzed using a unique error term, whereas simple main effects computed across between-participants factors were analyzed using a pooled error term. In the latter case, the pooled $M S_{\mathrm{e}}$ (and the resultant adjusted degrees of freedom) were calculated using a Microsoft Excel workbook downloaded from Baguley (2003). The degrees of freedom ( $d f \mathrm{~s})$ and sums of squares (SSs) entered into the worksheet came from the larger analysis that the simple main effect was intended to follow up (e.g., if the simple main effect is following up the main analysis of Phase 1, the $d f$ and $S S$ values are taken from the analysis of the Phase 1 data).

\section{Results}

The mean residual reading times for the region of interest in Phases 1 and 2 are presented in Figures 1 and 2, respectively. The results of the analyses described above are reported in Table 1. To keep the report of the statistical results manageable, only those analyses whose results are of theoretical importance are presented in the text. Where relevant, $M S_{\mathrm{e}}$ values are reported in the tables that summarize the statistical results. Effects reported as significant are significant at $p<.05$, unless otherwise noted. Analyses conducted by participants are denoted $F_{1}$, and analyses conducted by items are denoted $F_{2}$. Accuracy on the comprehension questions was $94.2 \%$.

Phase 1. The data from Phase 1 generally replicated the learning effect observed by Kaschak and Glenberg (2004). The training $\times$ time period interaction on the word given was significant by participants and was marginally significant by items $\left[F_{1}(2,92)=3.52 ; F_{2}(2,18)=\right.$
$2.54, p=.10]$. The participants in the needs training condition read the word given more slowly than did the participants in the control training condition during Critical Trials $1-3\left[F_{1}(1,108)=14.69, M S_{\mathrm{e}}=41,199 ; F_{2}(1,9)=\right.$ 7.84]. This difference was somewhat smaller on Critical Trials 4-7 and 8-10, being significant by items, but not by participants [Trials $4-7, F_{1}(1,108)=1.33, M S_{\mathrm{e}}=41,199$, $p=.24$, and $F_{2}(1,9)=6.45, M S_{\mathrm{e}}=3,439$; Trials 8-10, $F_{1}(1,108)=1.83, M S_{\mathrm{e}}=41,199, p=.17$, and $F_{2}(1,9)=$ $\left.8.05, M S_{\mathrm{e}}=4,325\right]$. By the end of Phase 1, the participants in both training conditions were processing the critical sentences with roughly equal facility. There was no difference in reading time for any of the other words in the region of interest for Critical Trials 8-10 (all $F_{1}$ values $<$ 1 , all $F_{2}$ values $<3.90, p>.08$ ).

Transfer: End of Phase 1 to first half of Phase 2. In moving from the end of Phase 1 to the beginning of Phase 2, the participants in the needs training condition did not generally show a significant slowing in reading times (except on the word that). The participants in the control training condition showed a significant slowing in reading times on the words given, that, and dinner.

Statistically, there was a time $\times$ training interaction on the words given $\left[F_{1}(1,46)=15.59 ; F_{2}(1,18)=17.40\right]$, that $\left[F_{1}(1,46)=13.03 ; F_{2}(1,18)=9.72\right]$, and dinner $\left[F_{1}(1,46)=4.66 ; F_{2}(1,18)=10.27\right]$. On the word given, the participants in the control condition slowed down in moving from the end of Phase 1 to the beginning of Phase $2\left[F_{1}(1,23)=29.84, M S_{\mathrm{e}}=25,141 ; F_{2}(1,35)=\right.$ $\left.42.84, M S_{\mathrm{e}}=7,582\right]$, but the participants in the needs training condition did not (all $F \mathrm{~s}<1$ ). On the word that, the participants in both training conditions slowed down in Phase 2 [control, $F_{1}(1,23)=46.70, M S_{\mathrm{e}}=10,090$, and $F_{2}(1,31)=32.35, M S_{\mathrm{e}}=5,512$; needs, $F_{1}(1,23)=15.08$, $M S_{\mathrm{e}}=4,273$, and $\left.F_{2}(1,31)=4.98, M S_{\mathrm{e}}=5,512\right]$, but the slowing in reading times was much greater for the par-

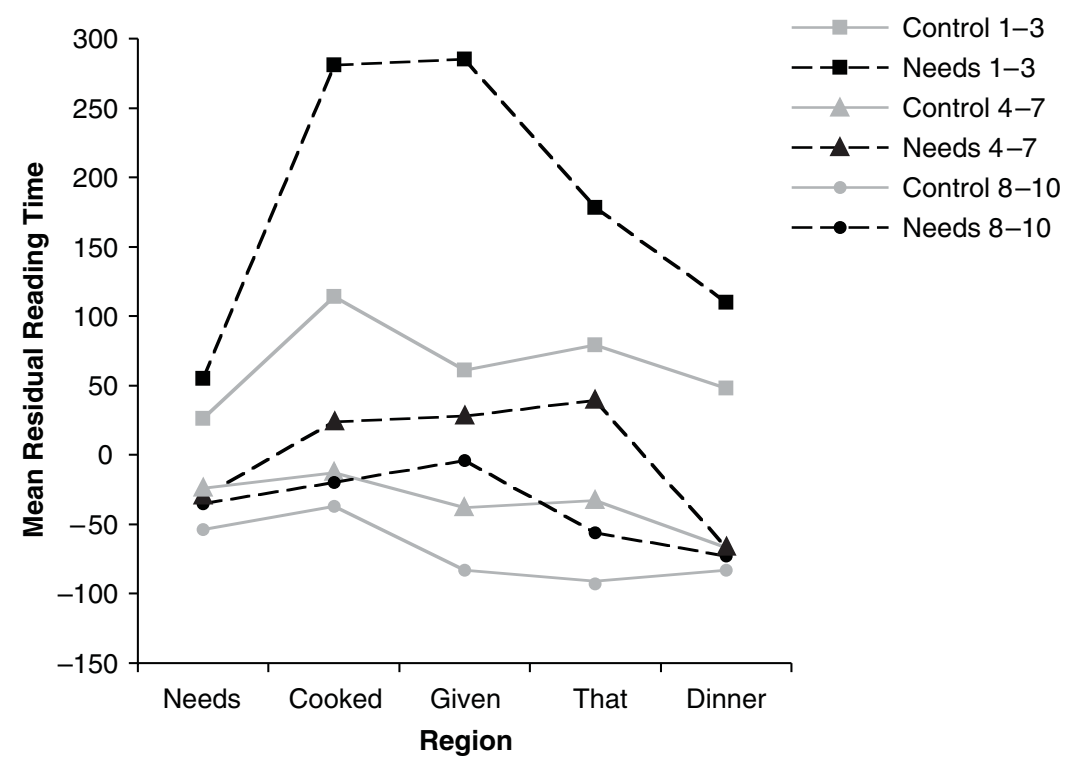

Figure 1. Mean residual reading times for Phase 1 of Experiment 1. 


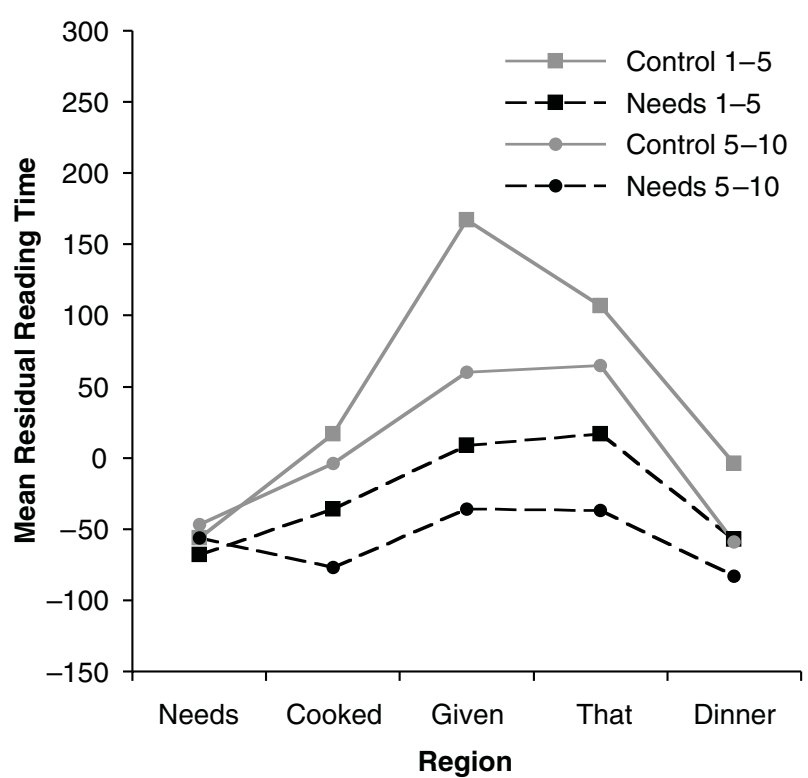

Figure 2. Mean residual reading times for Phase 2 of Experiment 1.

ticipants in the control condition. On the word dinner, the participants in the control training condition slowed down in Phase $2\left[F_{1}(1,23)=14.10, M S_{\mathrm{e}}=5,350 ; F_{2}(1,27)=\right.$ 12.02, $\left.M S_{\mathrm{e}}=2,534\right]$, but the participants in the needs training condition did not (all $F_{\mathrm{S}}<1$ ). There were no significant effects on the words needs or cooked (all $F$ values $<3.68, p>.07)$.
Phase 2. Analysis of the reading times from Phase 2 showed that the readers in the needs training condition read the pseudocleft needs sentences more quickly than did those in the control training condition on the words given $\left[F_{1}(1,46)=4.96 ; F_{2}(1,9)=21.09\right]$ and that $\left[F_{1}(1,46)=\right.$ $\left.5.47 ; F_{2}(1,9)=8.31\right]$. This effect was significant by items (but not by participants) on the words cooked $\left[F_{1}(1,46)=\right.$ $\left.1.09, p=.30 ; F_{2}(1,9)=5.40\right]$ and dinner $\left[F_{1}(1,46)=\right.$ $\left.1.95, p=.16 ; F_{2}(1,9)=20.08\right]$. The time $\times$ training interaction was not significant on any of the words in the region of interest, suggesting that the participants in the control training condition were reading the transfer sentences more slowly than were the participants in the needs training condition throughout Phase 2 of the experiment.

\section{Discussion}

Although the readers in the needs training condition showed a great deal of processing difficulty on the critical sentences at the beginning of Phase 1, by the end of this phase they were reading the novel needs construction about as quickly as the participants in the control condition were reading the needs to be construction. In the transfer phase of the experiment, the participants in the needs training condition experienced less difficulty than did the participants in the control condition when reading the construction in a pseudocleft form within a verb complement construction. The relative ease with which the participants in the needs training condition were able to handle the construction with a different surface and syntactic configuration suggests that their developing understanding of the needs construction was not tied to

Table 1

Statistical Analysis From Experiment 1

\begin{tabular}{|c|c|c|c|c|c|c|c|c|c|}
\hline \multirow[b]{2}{*}{ Region } & \multicolumn{3}{|c|}{ Time } & \multicolumn{3}{|c|}{ Training } & \multicolumn{3}{|c|}{ Time $\times$ Training } \\
\hline & $F_{1}$ & $M S_{\mathrm{e}}$ & $F_{2}$ & $F_{1}$ & $M S_{\mathrm{e}}$ & $F_{2}$ & $F_{1}$ & $M S_{\mathrm{e}}$ & $F_{2}$ \\
\hline \multicolumn{10}{|c|}{ Phase $1^{\mathrm{a}}$} \\
\hline Needs & $8.79^{*}$ & 11,321 & $5.71^{*}$ & $<1$ & - & 1.40 & $<1$ & - & $<1$ \\
\hline Cooked & $15.00^{*}$ & 47,844 & $29.74^{*}$ & 1.28 & 156,269 & $9.92^{*}$ & 1.66 & 47,844 & 1.53 \\
\hline Given & $24.75^{*}$ & 25,997 & $17.31^{*}$ & $7.71^{*}$ & 71,604 & $17.84^{*}$ & $3.52^{*}$ & 25,997 & 2.54 \\
\hline That & $22.07^{*}$ & 22,726 & $26.84^{*}$ & 2.14 & 79,660 & $18.16^{*}$ & $<1$ & - & $<1$ \\
\hline Dinner & $21.55^{*}$ & 15,275 & $20.65^{*}$ & 1.14 & 51,701 & $9.31^{*}$ & $<1$ & - & $<1$ \\
\hline \multicolumn{10}{|c|}{ Transfer: End of Phase 1 to Beginning of Phase $2^{\mathrm{b}}$} \\
\hline Needs & 1.04 & 6,983 & $<1$ & $<1$ & - & $<1$ & $<1$ & - & 3.68 \\
\hline Cooked & $<1$ & - & $<1$ & $<1$ & - & $<1$ & 1.45 & 20,704 & 2.47 \\
\hline Given & $19.18^{*}$ & 21,631 & $27.00^{*}$ & $<1$ & - & 1.84 & $15.59^{*}$ & 21,631 & $17.40^{*}$ \\
\hline That & $61.56^{*}$ & 7,181 & $22.63^{*}$ & $<1$ & - & 1.56 & $13.03^{*}$ & 7,181 & $9.72^{*}$ \\
\hline Dinner & $11.31^{*}$ & 4,946 & $5.04^{*}$ & $<1$ & - & 3.58 & $4.66^{*}$ & 4,946 & $10.27^{*}$ \\
\hline \multicolumn{10}{|c|}{ Phase $2^{c}$} \\
\hline Needs & $<1$ & - & $<1$ & $<1$ & - & $<1$ & $<1$ & - & $<1$ \\
\hline Cooked & 1.54 & 15,334 & $<1$ & 1.09 & 88,823 & $5.40^{*}$ & $<1$ & - & $<1$ \\
\hline Given & $7.11^{*}$ & 19,562 & $8.38^{*}$ & $4.96^{*}$ & 77,739 & $21.09^{*}$ & 1.18 & 19,562 & 1.28 \\
\hline That & 3.88 & 14,281 & 2.10 & $5.47^{*}$ & 49,618 & 8.31 & $<1$ & - & $<1$ \\
\hline Dinner & $8.71^{*}$ & 4,818 & $6.11^{*}$ & 1.95 & 18,137 & $20.08^{*}$ & $<1$ & - & 1.45 \\
\hline
\end{tabular}

Note- $M S_{\mathrm{e}}$ values are reported for by-participants analyses only. $M S_{\mathrm{e}} \mathrm{s}$ are not presented when the $F$ value $<1$. Significant effects $(p<.05)$ are marked with an asterisk. aThe degrees of freedom $(d f \mathrm{~s})$ for Phase 1 analyses by participants are the following: time and time $\times$ training $(2,92)$; training $(1,46)$. The $d f$ s for analyses by items are the following: time and time $\times$ training $(2,18)$; training $(1,9)$. ${ }^{\mathrm{b}}$ The $d f \mathrm{~s}$ for transfer analyses by participants are $(1,46)$ for all factors. The $d f \mathrm{~s}$ for analyses by items are $(1,18)$ for all factors. ${ }^{\mathrm{c}}$ The $d f \mathrm{~s}$ for Phase 2 analyses by participants are $(1,46)$ for all factors. The $d f$ s for analyses by items are $(1,9)$ for all factors. 
the surface features of the construction as it was initially encountered. Rather, they apparently had developed an abstract representation of the construction that could be subjected to the same syntactic principles as those that were applied to other constructions in their grammar. Furthermore, these data provide the first demonstration that structural priming-like effects in language comprehension can occur across sentential contexts (but see Branigan et al., in press, for a demonstration of this phenomenon in language production).

It is interesting to note the lack of significant time $\times$ training interactions in Phase 2 of the experiment. Although the participants in the control condition received training on the pseudocleft needs sentences, they did not show processing gains, relative to the participants in the needs training condition. The lack of a learning effect in Phase 2 suggests that the needs construction may be more difficult to learn when first encountered in a form more syntactically complicated than the canonical active sentences used in Phase 1 of these experiments. Although the data at hand do not speak directly to this issue, one explanation for this finding is that the surface structure of the pseudocleft needs sentences makes it more difficult for learners to use their knowledge of the needs to be construction to adapt to the novel construction.

\section{EXPERIMENT 2}

Experiment 2 was designed to lend further credence to the claim that the participants trained on the needs construction acquire abstract knowledge about the construction. The experiment replicated Experiment 1, except that the transfer sentences now used the verb wants:

\section{John thinks that what the dog wants is walked before it} gets too late.

The verb wants was used to parallel natural patterns of usage for the needs construction (some native speakers of the needs construction also use it with the verb wants; Murray \& Simon, 2001). Thus, testing for generalization to this verb allowed for an experimental test that had some connection to the situation that comprehenders might face outside the lab. In addition, Kaschak and Glenberg (2004) had previously shown that the needs construction can transfer to wants, providing a precedent for predicting that transfer across verbs should also occur in this experiment. On a more general level, the shared semantic features and similar pattern of usage across English constructions for needs and wants (see Levin, 1993) provided a basis for expecting that a construction learned via one of the verbs might readily be extended to the other (Fisher, 1996, discusses mechanisms that may support extension of a construction to new verbs).

The motivation for this experiment was twofold. First, when the participants read "... what the meal needs ..." in Phase 2 of Experiment 1, the similarity between the training sentences and the transfer sentences was somewhat transparent. In this experiment, the participants encountered the construction through such phrases as "... what the dog wants...," which differed from the training sentences in both the animacy of the subject (it was animate in the transfer sentences but inanimate in the training sentences) and the verb that was used (needs vs. wants). Thus, observation of transfer effects such as those seen in Experiment 1 would provide a stronger demonstration that the participants had learned something abstract about the needs construction. The second motivation for this experiment was that one of the hallmarks of structural priming is that it occurs across changes in the lexical content of the sentences (see, e.g., Bock \& Griffin, 2000; Pickering \& Branigan, 1998). If the effect observed in Experiment 1 was the result of structural priming in language comprehension (as was claimed), it should replicate in a situation in which the lexical content of the transfer sentences (particularly the verb) was changed.

\section{Method}

Participants. The participants were 48 introductory psychology students from Florida State University (24 in each training condition). The students received course credit in exchange for their participation.

Materials. The materials were the same as those used in Experiment 1, except that new transfer sentences (such as Sentence 5) were written (see the Appendix).

Procedure. The procedure was identical to that in Experiment 1 .

Design and Analysis. The data analysis was identical to that in Experiment 1.

\section{Results}

The mean residual reading times for the regions of interest in Phase 1 and Phase 2 are presented in Figures 3 and 4 , respectively. The results of the three primary analyses are reported in Table 2. Accuracy on the comprehension questions was $92.4 \%$.

Phase 1. The data from Phase 1 show the same overall pattern as that in Experiment 1 . The time $\times$ training interaction on the word given was significant in the analysis by participants and was marginally significant in the analysis by items $\left[F_{1}(2,92)=3.95 ; F_{2}(2,18)=2.73, p=.09\right]$. The participants in the needs training condition read the word given more slowly than did the participants in the control training condition during Critical Trials $1-3\left[F_{1}(1,98)=\right.$ $\left.6.59, M S_{\mathrm{e}}=78,941 ; F_{2}(1,9)=6.47, M S_{\mathrm{e}}=25,939\right]$, but this difference disappeared during Critical Trials 4-7 $\left[F_{1}<1 ; F_{2}(1,9)=2.48, M S_{\mathrm{e}}=6,656, p=.15\right]$ and Critical Trials $8-10\left(F_{1}\right.$ and $\left.F_{2}<1\right)$. Reading times for the critical sentences did not differ across training conditions for the other words in the region of interest in Trials 8-10 (all $F_{1}$ values $<1$, all $F_{2}$ values $<3.51, p>.09$ ).

Transfer: End of Phase 1 to first half of Phase 2. Although the results from the end of Phase 1 to the beginning of Phase 2 are not as strong (statistically) as those in Experiment 1, the same pattern was observed: The participants in the control training condition showed a trend toward slower reading times in moving from Phase 1 to Phase 2, whereas the participants in the needs training condition did not. 


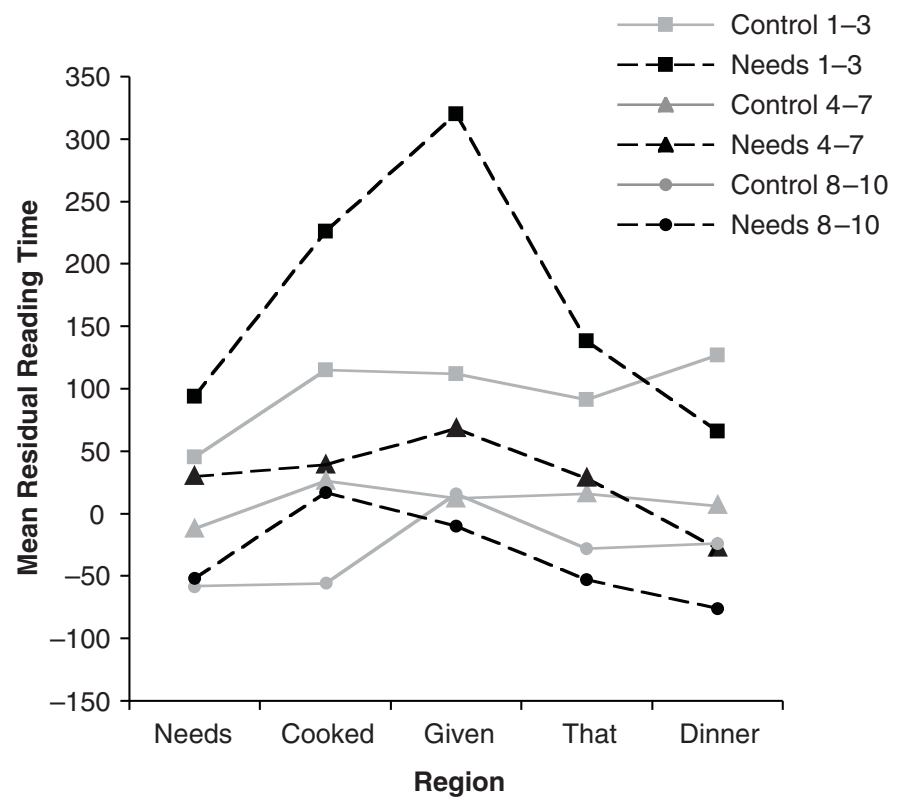

Figure 3. Mean residual reading times for Phase 1 of Experiment 2.

Statistically, there was a time $\times$ training interaction on the word cooked $\left[F_{1}(1,46)=6.47 ; F_{2}(1,18)=12.07\right]$. The participants in the control training condition slowed down in moving from Phase 1 to Phase 2, although this effect was only marginally significant $\left[F_{1}(1,23)=4.15\right.$, $M S_{\mathrm{e}}=21,413, p=.053 ; F_{2}(1,32)=3.21, M S_{\mathrm{e}}=13,811$, $p=.08]$. The participants in the needs training condition sped up in moving from Phase 1 to Phase 2, although the effect was only marginally significant in the analysis by

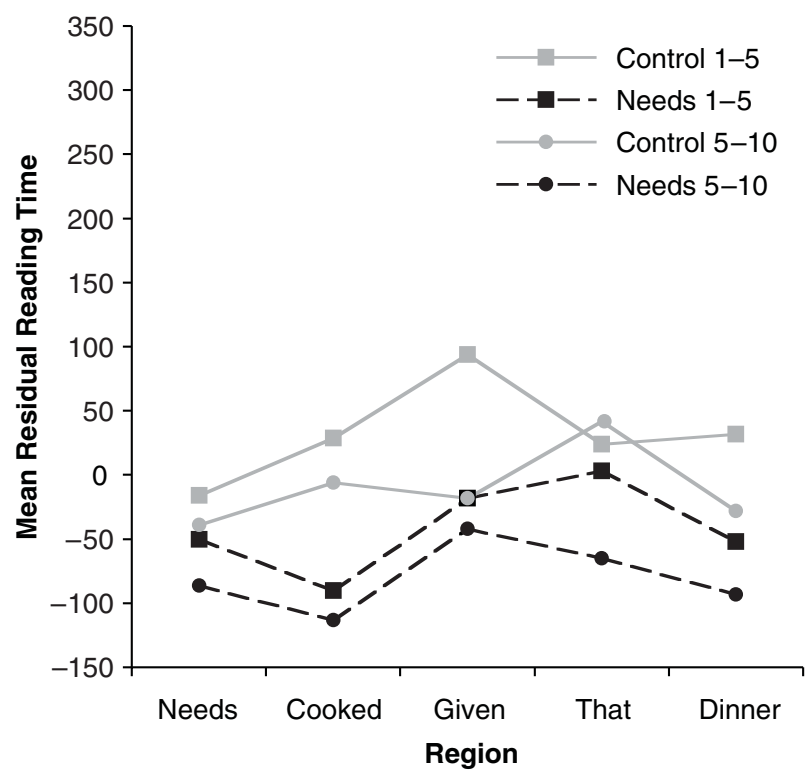

Figure 4. Mean residual reading times for Phase 2 of Experiment 2. participants $\left[F_{1}(1,23)=2.99, M S_{\mathrm{e}}=45,939, p=.097\right.$; $\left.F_{2}(1,32)=4.97, M S_{\mathrm{e}}=13,811\right]$. The participants in the needs training condition did not show significant differences in moving between Phase 1 and Phase 2 in any other region of the sentence [all $F_{1}$ values $<3.32, p>.08$; all $F_{2}$ values $\left.<2.82, p>.10\right]$. The participants in the control training condition showed a trend toward slower reading times in moving from Phase 1 to Phase 2 in all regions of the sentence. On the word needs, this difference was significant in the analysis by participants only $\left[F_{1}(1,23)=\right.$ $8.35, M S_{\mathrm{e}}=2,676 ; F_{2}(1,28)=2.24, M S_{\mathrm{e}}=5,268, p=$ $.15]$. On the word given, the difference was marginally significant by participants and items $\left[F_{1}(1,23)=4.05\right.$, $M S_{\mathrm{e}}=17,403, p=.056 ; F_{2}(1,35)=3.56, M S_{\mathrm{e}}=11,876$, $p=.067]$. On the word that, the difference was significant by participants and marginally so by items $\left[F_{1}(1,23)=\right.$ $6.70, M S_{\mathrm{e}}=4,970 ; F_{2}(1,36)=2.93, M S_{\mathrm{e}}=5,115, p=$ .095]. On the word dinner, the difference was marginally significant by participants and items $\left[F_{1}(1,23)=3.11\right.$, $M S_{\mathrm{e}}=12,336, p=.091 ; F_{2}(1,36)=3.93, M S_{\mathrm{e}}=3,429$, $p=.055]$.

Phase 2. The participants in the needs training condition generally read the transfer sentences more quickly than did the participants in the control training condition. This difference was significant by items and was marginally significant by participants on the words cooked $\left[F_{1}(1,46)=3.86, p=.056 ; F_{2}(1,9)=39.23\right]$ and dinner $\left[F_{1}(1,46)=3.96, p=.053 ; F_{2}(1,9)=57.70\right]$. The difference between training conditions was significant by items, but not by participants, on the words needs $\left[F_{1}(1,46)=\right.$ $\left.1.12, p=.30 ; F_{2}(1,9)=9.47\right]$, given $\left[F_{1}(1,46)=1.37\right.$, $\left.p=.25 ; F_{2}(1,9)=7.65\right]$, and that $\left[F_{1}(1,46)=2.74, p=\right.$ $\left..11 ; F_{2}(1,9)=22.82\right]$. As in Experiment 1 , the time $\times$ training interaction was not significant in any region of 
Table 2 Statistical Analysis From Experiment 2

\begin{tabular}{|c|c|c|c|c|c|c|c|c|c|}
\hline \multirow[b]{2}{*}{ Region } & \multicolumn{3}{|c|}{ Time } & \multicolumn{3}{|c|}{ Training } & \multicolumn{3}{|c|}{ Time $\times$ Training } \\
\hline & $F_{1}$ & $M S_{\mathrm{e}}$ & $F_{2}$ & $F_{1}$ & $M S_{\mathrm{e}}$ & $F_{2}$ & $F_{1}$ & $M S_{\mathrm{e}}$ & $F_{2}$ \\
\hline \multicolumn{10}{|c|}{ Phase $1^{\mathrm{a}}$} \\
\hline Needs & $17.26^{*}$ & 11,028 & $8.32^{*}$ & $<1$ & - & 2.47 & $<1$ & - & $<1$ \\
\hline Cooked & $12.23^{*}$ & 37,953 & $10.74^{*}$ & $<1$ & - & 4.13 & $<1$ & - & $<1$ \\
\hline Given & $14.38^{*}$ & 43,474 & $18.10^{*}$ & 1.49 & 149,878 & $9.49^{*}$ & $3.95^{*}$ & 43,474 & 2.73 \\
\hline That & $23.16^{*}$ & 12,696 & $11.26^{*}$ & $<1$ & - & $<1$ & 1.22 & 12,696 & $<1$ \\
\hline Dinner & $18.51^{*}$ & 15,109 & $19.02^{*}$ & 1.19 & 73,345 & $8.72^{*}$ & $<1$ & - & $<1$ \\
\hline \multicolumn{10}{|c|}{ Transfer: End of Phase 1 to Beginning of Phase $2 \mathrm{~b}$} \\
\hline Needs & 2.11 & 5,982 & $<1$ & $<1$ & - & $<1$ & 1.64 & 5,892 & 2.44 \\
\hline Cooked & $<1$ & - & $<1$ & $<1$ & - & $<1$ & $6.65^{*}$ & 33,676 & $12.07^{*}$ \\
\hline Given & 1.61 & 18,225 & 1.61 & 1.06 & 108,990 & 2.66 & 2.29 & 18,225 & 2.03 \\
\hline That & $8.68^{*}$ & 8,170 & $5.28^{*}$ & $<1$ & - & 1.22 & $<1$ & - & $<1$ \\
\hline Dinner & $4.92^{*}$ & 8,108 & 3.73 & 2.85 & 38,491 & $11.06^{*}$ & $<1$ & 4,946 & $<1$ \\
\hline \multicolumn{10}{|c|}{ Phase $2^{c}$} \\
\hline Needs & 2.42 & 8,583 & 1.88 & 1.11 & 35,999 & $9.47^{*}$ & $<1$ & - & $<1$ \\
\hline Cooked & 1.97 & 10,655 & 1.39 & 3.86 & 79,325 & $39.23^{*}$ & $<1$ & - & $<1$ \\
\hline Given & $5.27^{*}$ & 18,728 & 3.21 & 1.37 & 79,614 & $7.65^{*}$ & 2.47 & 18,728 & 2.35 \\
\hline That & 1.30 & 11,571 & 1.57 & 2.74 & 40,618 & $22.82^{*}$ & 3.81 & 11,571 & 3.96 \\
\hline Dinner & $7.27^{*}$ & 8,493 & $7.91^{*}$ & 3.96 & 33,769 & $57.70^{*}$ & $<1$ & - & $<1$ \\
\hline
\end{tabular}

Note $-M S_{\mathrm{e}}$ values are reported for by-participants analyses only. $M S_{\mathrm{e}}$ s are not presented when $F<1$. Significant effects $(p<.05)$ are marked with an asterisk. aThe degrees of freedom $(d f \mathrm{~s})$ for Phase 1 analyses by participants are the following: time and time $\times$ training $(2,92)$; training $(1,46)$. The $d f$ s for analyses by items are the following: time and time $\times$ training $(2,18)$; training $(1,9)$. bThe $d f$ s for transfer analyses by participants are $(1,46)$ for all factors. The $d f$ s for analyses by items are $(1,18)$ for all factors. cThe $d f$ s for Phase 2 analyses by participants are $(1,46)$ for all factors. The $d f$ s for analyses by items are $(1,9)$ for all factors.

the sentence, although it was marginally significant on the word that $\left[F_{1}(1,46)=3.81, p=.057 ; F_{2}(1,9)=3.96\right.$, $p=.078]$. Whereas the participants in the needs training condition continued to speed up in reading across Phase 2 , the participants in the control training condition slowed down.

Finding significant effects on the verb of the transfer sentences (wants), where the participants in the control condition slowed down in moving from Phase 1 to Phase 2 and read this word more slowly than did the participants in the needs training condition in Phase 2, was unexpected, because the earliest point of reading difficulty should have been at the word cooked, when the participants in the control condition first encountered the novel construction. One explanation for this effect is that the participants in the control condition slowed down on the word wants because it indicated the coming of the unusual pseudocleft needs construction. Since wants appeared in the experiment for the first time in these difficult sentences (and appeared only in these sentences), the participants may have begun to slow down in their reading times for this word in anticipation of the difficultly that was to come. ${ }^{3}$ In spite of this anticipation, it seems reasonable to expect that the participants in the control training condition would still experience processing difficulty on the word cooked, because of the difficulty of dealing with the new construction. If it is the case that the participants slowed down on wants in anticipation of the novel construction but slowed down even further on cooked because of the difficulty of dealing with the new construction, an interaction between sentence region (wants vs. cooked) and training condition should be observed, with the difference between training conditions being greater on the word cooked than on the word wants. This prediction was borne out by statistical analysis across the two sentence regions $\left[F_{1}(1,46)=3.88, M S_{\mathrm{e}}=8,034\right.$, $\left.p=.055 ; F_{2}(1,9)=21.52, M S_{\mathrm{e}}=726\right]$. Thus, it seems unlikely that the effect on cooked was simply a carryover from the effect that was observed on wants.

\section{Discussion}

In Phase 2, the participants in the needs training condition showed little sign of processing difficulty when they first encountered the transfer sentences, and they read the transfer sentences more quickly than did the participants in the control training condition. These results suggest that the participants in the needs training condition were able to generalize the construction to a pseudocleft form (presented within a sentence complement construction) even though the transfer sentences differed from the training sentences in several ways (e.g., the animacy of the subject and the verb used in the construction). This result further supports the claim that the readers in the needs training condition have acquired knowledge about the construction that is not tied to the particular sentential context in which the construction was encountered during training.

A noteworthy component of these results (and the results of Experiment 1) is that many of the effects were stronger in the analysis by items than in the analysis by participants. This may be due to differences in statistical power across analyses, since many of the analyses are between participants but within items. Another possibility is that the weaker by-participants effects are indicative 
of individual differences that arise in the processing of the novel construction. Readers may differ in the speed with which they are able to learn the new construction, in their ability to generalize the construction, in their ability to recover from garden paths, or on some other dimension relevant to the task. Because no effort was made to monitor individual difference variables, it is not possible to say which (if any) of these variables may have affected performance in the experiments presented here. This will be an interesting issue to explore in future studies.

\section{GENERAL DISCUSSION}

The data reported here extend our understanding of the knowledge that readers acquire as they learn to comprehend a novel construction in several ways. First, participants acquire abstract knowledge about the structure of the construction, rather than simply learning a rule about its surface structure. Second, the representation of the needs construction appears to be subject to the kinds of syntactic principles that participants apply to other constructions in their grammar. Third, knowledge of the needs construction is not tied to the sentential context in which it was initially experienced. These conclusions are supported by the finding that readers who are trained on the needs construction through examples structured as canonical active sentences can straightforwardly comprehend examples of the construction in a pseudocleft form presented within the subordinate clause of a verb complement construction, even across changes in the lexical content of the sentences.

The finding that repeated exposure to the needs construction facilitates the processing of subsequent examples of the construction is consonant with observations of syntactic priming in language production (e.g., Bock, 1986; Bock \& Griffin, 2000; Griffin \& Weinstein-Tull, 2003; Pickering \& Branigan, 1998) and comprehension (e.g., Branigan et al., 2005; Carey et al., 1970). Two theories of structural priming have been proposed. Pickering and Branigan (1998) argued that structural priming arises via activation of syntactic information associated with particular lexical items. For example, when someone says "The man gave the girl a candy bar," there is activation of the verb give and its associated syntactic information (e.g., the tense, aspect, and subcategorization properties of the verb). This activation decays gradually. While the activation remains elevated, it exerts an influence on the production of subsequent sentences. In this case, activation of give and the accompanying subcategorization properties would prime the production of a double-object sentence to convey the message that someone transferred something to someone else. Although Pickering and Branigan did not develop this theory as a model of sentence comprehension, one can easily imagine a similar account being offered for structural priming in comprehension. Upon comprehending a sentence such as "The man gave the girl a candy bar," the syntactic information associated with this use of give is activated. This activation facilitates the comprehension of subsequent sentences that have a matching structure.
Bock and colleagues (e.g., Bock \& Griffin, 2000; Chang, Dell, Bock, \& Griffin, 2000) offer an alternative account of structural priming, in which structural priming is viewed as a case of implicit learning within the language production system. Chang et al. implemented this account in a connectionist model. The model was trained to produce sentences from message-level conceptual structures. Structural priming was produced by leaving the learning algorithm on throughout the production task. Thus, each sentence that was produced resulted in a change in the model weights, which biased the system to use the same structure when it produced subsequent utterances. On this account, the learning algorithm through which the model acquires the ability to produce sentences is the same as the mechanism that gives rise to structural priming. For this reason, Bock and Griffin spoke of structural priming as a vestige of the process of learning to talk, much in the same way that the results of the experiments presented here (and in Kaschak \& Glenberg, 2004) have been described as learning to comprehend.

Both of these theories would need to be modified or clarified beyond their current instantiations in order to account for the data presented here. Pickering and Branigan's (1998) model is designed to account for short-term priming effects (the activation of syntactic features is proposed to decay within a few seconds), not to be a model of learning. To account for these data, a modified version of the theory would need to incorporate a mechanism through which new nodes could be developed to represent the new features of a novel construction, as well as a mechanism that would allow for relatively long-term changes in the strength of links between particular classes of lexical items (such as verbs) and particular syntactic features (the latter possibility has already been discussed by Pickering, Branigan, Cleland, \& Stewart, 2000).

Because Chang et al.'s (2000) model is built on a mechanism capable of long-term learning, it provides a straightforward way to capture the learning of a new construction. However, in the absence of detailed simulations, it is difficult to ascertain whether the model would generalize the needs construction across verbs and to the pseudocleft form with no (or very little) processing difficulty, as the participants in these experiments did. The operation of the context layer in this model may function to restrict learning of the needs construction to the sentential context in which it first appeared, making generalization of the construction to a new sentential context (as in Phase 2 of these experiments) difficult. Further development of the model is needed to clarify these issues.

Among the extant models of sentence comprehension, the best candidate to apply to the learning of the needs construction is the constraint satisfaction account (e.g., MacDonald et al., 1994; McRae, Spivey-Knowlton, \& Tanenhaus, 1998). Constraint satisfaction theories serve as models of both sentence comprehension and learning within the comprehension system, and therefore provide a mechanism through which the learning of the needs construction can be explained. Nonetheless, without detailed simulations, it is difficult to know whether constraint satisfaction models would generalize the needs construction 
in the same manner as that evidenced by the participants in these experiments. On the one hand, constraint-based models predict that online sentence processing will be affected by the relative frequency with which particular verbs have been used in particular constructions (e.g., Garnsey et al., 1997; Trueswell, Tanenhaus, \& Kello, 1993). From this perspective, the models might not generalize the construction from needs to wants with as little difficulty as was seen in Experiment 2. On the other hand, connectionist models are generally good at making generalizations, which argues that they would generalize the needs construction with little difficulty.

The data reported here are consistent with a growing body of work showing that linguistic knowledge does not become fixed at some point during the life span (e.g., Dell, Reed, Adams, \& Meyer, 2000; Kaschak \& Glenberg, 2004; Labov, 1994). It continues to change as the nature of one's experience with language (and one's linguistic environment) changes. Adaptation within the adult language processing system has been observed under a range of circumstances. Dell et al. (2000) have shown that language users can adapt to a new set of phonotactic constraints in a language production task. Kaschak and Glenberg (2004) have demonstrated that readers can adapt to new syntactic constructions. Garrod and colleagues (e.g., Garrod \& Anderson, 1987; Garrod \& Doherty, 1994) have reported a series of studies in which language users develop a new set of linguistic conventions while performing a cooperative task. On the basis of these observations, several researchers have suggested that the learning mechanisms that support language acquisition in children remain operative well into adulthood (e.g., Bock \& Griffin, 2000; Brooks \& Tomasello, 1999; Kaschak \& Glenberg, 2000, 2004; Seidenberg \& MacDonald, 1999).

After a handful of exposures to the needs construction, readers readily comprehended the construction when it appeared with a different surface form in a different sentential context. This suggests that readers quickly acquire abstract structural knowledge about the construction that can be applied in a range of contexts. These observations serve to further our understanding of the changes that occur as the language comprehension system adapts to novel linguistic forms and serves as another demonstration that language processing systems continue to adapt to changes in one's linguistic environment throughout the life span.

\section{REFERENCES}

Baguley, T. (2003). Simple main effects in ANOVA. Retrieved December 9, 2003 from www-staff.lboro.ac.uk/ hutsb/simple.htm.

Bock, J. K. (1986). Syntactic persistence in language production. Cognitive Psychology, 18, 355-387.

Bock, [J.] K. (1989). Closed-class imminence in sentence production. Cognition, 31, 163-186.

Bock, [J.] K., \& GRIFFIN, Z. M. (2000). The persistence of structural priming: Transient activation or implicit learning? Journal of Experimental Psychology: General, 129, 177-192.

Branigan, H. P., Pickering, M. J., \& Cleland, A. A. (2000). Syntactic co-ordination in dialogue. Cognition, 75, B13-B25.

Branigan, H. P., Pickering, M. J., \& Mclean, J. F. (2005). Prim- ing prepositional-phrase attachment during comprehension. Journal of Experimental Psychology: Learning, Memory, \& Cognition, 31, 468-481.

Branigan, H. P., Pickering, M. J., Mclean, J. F., \& Stewart, A. J. (in press). The scope of grammatical encoding during language production: Evidence from syntactic priming. Language \& Cognitive Processes.

Brooks, P. J., \& Tomasello, M. (1999). Young children learn to produce passives with nonce verbs. Developmental Psychology, 35, 29-44.

Carey, P. W., Mehler, J., \& Bever, T. G. (1970). Judging the veracity of ambiguous sentences. Journal of Verbal Learning \& Verbal Behavior, 9, 243-254.

Chaffin, R., Morris, R. K., \& Seely, R. E. (2001). Learning new word meanings from context: A study of eye movements. Journal of Experimental Psychology: Learning, Memory, \& Cognition, 27, 225-235.

Chang, F., Dell, G. S., Bock, K., \& Griffin, Z. M. (2000). Structural priming as implicit learning: A comparison of models of sentence production. Journal of Psycholinguistic Research, 29, 217-229.

Cleland, A. A., \& Pickering, M. J. (2003). The use of lexical and syntactic information in language production: Evidence from the priming of noun phrase structure. Journal of Memory \& Language, 49, 214-230.

Cleland, A. A., \& Pickering, M. J. (2006). Do writing and speaking employ the same syntactic representations? Journal of Memory \& Language, 54, 185-198.

Dell, G. S., Reed, K. D., Adams, D. R., \& Meyer, A. S. (2000). Speech errors, phonotactic constraints, and implicit learning: A study of the role of experience in language production. Journal of Experimental Psychology: Learning, Memory, \& Cognition, 26, 1355-1367.

FerreIRA, V. (2003). The persistence of optional complementizer production: Why saying "that" is not saying "that" at all. Journal of Memory \& Language, $\mathbf{4 8}, 379-398$.

FISHER, C. (1996). Structural limits on verb mapping: The role of analogy in children's interpretations of sentences. Cognitive Psychology, 31, 41-81.

Frazier, L., \& Clifton, C. (1996). Construal. Cambridge, MA: MIT Press.

Garnsey, S. M., Pearlmutter, N. J., Myers, E., \& Lotocky, M. A. (1997). The contributions of verb bias and plausibility to the comprehension of temporarily ambiguous sentences. Journal of Memory \& Language, 37, 58-93.

Garrod, S., \& Anderson, A. (1987). Saying what you mean in dialogue: A study in conceptual and semantic co-ordination. Cognition, 27, 181-218.

Garrod, S., \& Doherty, G. (1994). Conversation, co-ordination and convention: An empirical investigation of how groups establish linguistic conventions. Cognition, 53, 181-215.

Griffin, Z. M., \& Weinstein-TulL, J. (2003). Conceptual structure modulates structural priming in the production of complex sentences. Journal of Memory \& Language, 49, 537-555.

KaschaK, M. P., \& GlenberG, A. M. (2000). Constructing meaning: The role of affordances and grammatical constructions in sentence comprehension. Journal of Memory \& Language, 43, 508-529.

KaschaK, M. P., \& GlenberG, A. M. (2004). This construction needs learned. Journal of Experimental Psychology: General, 133, 450467.

KaschaK, M. P., Loney, R. A., \& Borreggine, K. L. (2006). Recent experience affects the strength of structural priming. Cognition, 99, B73-B82.

KepPel, G. (1991). Design and analysis: A researcher's handbook (3rd ed.). Englewood Cliffs, NJ: Prentice Hall.

Labov, W. (1994). Principles of linguistic change: Vol. 1. Internal factors. Cambridge, MA: Blackwell.

Levin, B. (1993). English verbs. Chicago: University of Chicago Press. MacDonald, M. C., Pearlmutter, N. J., \& Seidenberg, M. S. (1994). Lexical nature of syntactic ambiguity resolution. Psychological Review, 101, 676-703.

McRae, K., Spivey-Knowlton, M. J., \& Tanenhaus, M. K. (1998). Modeling the influence of thematic fit (and other constraints) in online sentence comprehension. Journal of Memory \& Language, 38, 283-312. 
Murray, T. E., Frazier, T. C., \& Simon, B. L. (1996). Need + past participle in American English. American Speech, 71, 255-271.

MurRaY, T. E., \& Simon, B. L. (2001). At the intersection of regional and social dialects: The case of like + past participle in American English. American Speech, 77, 32-69.

NygaARD, L. C., \& PIsOnI, D. B. (1998). Talker-specific learning in speech perception. Perception \& Psychophysics, 60, 355-376.

Pickering, M. J., \& Branigan, H. P. (1998). The representation of verbs: Evidence from syntactic priming in language production. Journal of Memory \& Language, 39, 633-651.

Pickering, M. J., Branigan, H. P., Cleland, A. A., \& Stewart, A. J. (2000). Activation of syntactic information during language production. Journal of Psycholinguistic Research, 29, 205-216.

Savage, C., Lieven, E., Theakston, A., \& Tomasello, M. (2003). Testing the abstractness of children's linguistic representations: Lexical and structural priming of syntactic constructions in young children. Developmental Science, 6, 557-567.

SeidenberG, M. S., \& MacDonald, M. C. (1999). A probabilistic constraints approach to language acquisition and processing. Cognitive Science, 23, 569-588.

Trueswell, J. C., Tanenhaus, M. K., \& Kello, C. (1993). Verbspecific constraints in sentence processing: Separating effects of lexi- cal preference from garden-paths. Journal of Experimental Psychology: Learning, Memory, \& Cognition, 19, 528-553.

\section{NOTES}

1. Throughout this article, the term learn to comprehend is used to describe the performance of the participants trained on the needs construction. This term is meant to distinguish the learning that occurs in these experiments from claims that the participants have acquired the construction. The term acquisition is better reserved for cases in which the learner can both comprehend and produce the structure in question. Because no attempt is made to monitor the language production of these participants, the most conservative claim about the participants' behavior is that their learning is restricted to the operation of the comprehension system.

2. Thanks to an anonymous reviewer for this suggestion.

3. Note that this strategy would not be effective for the control participants in Experiment 1, where the verb needs would not necessarily signal the onset of an unusual construction. Because needs had been encountered in the familiar needs to be construction in Phase 1, the participants in the control training condition would need to wait until later in the sentence to determine whether they were reading the unusual construction. 


\section{APPENDIX \\ Critical Sentences in Experiments 1 and 2}

The sentences used in Experiments 1 and 2 are presented below. Note that for all training sentences, the needs versions are presented. The control version of the sentence can be generated by adding a "to be" after "needs."

\section{Needs Training Sentences (Phase 1, Experiments 1 and 2)}

1. The wood floor needs cleaned before our parents get here.

2. The white walls need painted to keep the tenants happy.

3. The old chair needs fixed so the guests can sit on it.

4. The computer program needs debugged before I hand it in.

5. Florida oranges need peeled before they can be eaten.

6. The large pumpkin needs carved before it can be put on display.

7. Small potatoes need boiled before they can be used in the soup.

8. The term paper needs revised before tomorrow morning.

9. The blank CD needs burned so I can give it to you.

10. The green light bulb needs changed since it just burned out.

\section{Needs Transfer Sentences (Phase 2, Experiment 1)}

1. Jorge thinks that what the tile needs is washed before it can be put on the wall.

2. Pete said that what the cabinet needs is dusted when you clean the living room.

3 . The secretary wondered if what the file needs is completed since the case is closed.

4. She feels that what the bench needs is folded before it is put away.

5. I think that what the pie needs is baked so we can serve it.

6. The coach said that what the ball needs is inflated before we can play the game.

7. The carpenter said that what the screws need is tightened to keep the deck safe.

8. The clerk said that what the wine needs is refrigerated so that it will not go bad.

9. Mom said that what the meal needs is cooked given that dinner is in an hour.

10. The designer suggested that what the picture needs is trimmed to fit into the frame.

\section{Wants Transfer Sentences (Phase 2, Experiment 2)}

1. Jorge thinks that what the dog wants is walked before it is time for us to leave.

2. Pete said that what the kitten wants is scratched before she eats her dinner.

3. The waitress knows that what the customer wants is served before everyone else in the restaurant.

4. The press knows that what the hero wants is recognized for his acts of great valor.

5. I think that what the parrot wants is fed before he will talk again.

6. The parent said that what the child wants is treated by the doctor to cure her flu.

7. His colleagues know that what the scientist wants is photographed for the school paper's big issue.

8. The owner knows that what the chef wants is praised for her extraordinary recipe for chicken gumbo.

9. Mom said that what the baby wants is held because he is feeling uneasy.

10. The general feels that what the colonel wants is honored for his years of service.

(Manuscript received March 25, 2004;

revision accepted for publication February 22, 2005.) 